\title{
Vamos comer Shakespeare: a devoração do Bardo em Trabalhos de amor perdidos, de Jorge Furtado
}

\author{
Raquel Cristina do N. Pinho e Fernanda Teixeira de Medeiros
}

\section{Introdução}

O processo de adaptação envolve uma série de transposições culturais, temporais, geográficas, históricas e, não raramente, também inclui a transição de um gênero para outro. Ele abarca múltiplas camadas, correspondências irregulares, comentários e adições ao texto-fonte, além de ecos que trazem outros elementos intertextuais à baila. Trata-se, portanto, de um jogo dialógico complexo, que implica muito mais uma atividade criativa, analítica e crítica do que uma mera "repaginada" maquinal, repetitiva e inábil. No caso de Trabalhos de amor perdidos (2006), obra que integra a coleção Devorando Shakespeare, da editora Objetiva, Jorge Furtado revisita a peça homônima ${ }^{1}$ de William Shakespeare $(1564$ - 1616) de forma descontraída, fazendo um pot-pourri de gêneros e desafiando os limites da "infidelidade" em sua relação com o texto-fonte.

Nosso objetivo neste artigo é investigar a relação que se estabelece entre o romance de Furtado e a comédia de Shakespeare, examinando pontos de encontro e desencontro, comentando a construção de personagens e analisando o manuseio do texto-fonte e sua subsequente "devoração". Por fim, tenciona-se analisar as aparentes "traições" que Furtado realiza para construir sua história, evidenciando sua adaptação

\footnotetext{
${ }^{1}$ Título original: Love's Labour's Lost (1595-96)
} 
como obra de riqueza singular e fruto de uma leitura minuciosa e produtiva da comédia shakespeariana ${ }^{2}$.

\section{"Doutor, doutor, meu filho engoliu Shakespeare, o que eu faço?"3}

Trabalhos de amor perdidos (2006), do cineasta, roteirista e escritor portoalegrense Jorge Furtado, é o primeiro volume de uma série lançada pela editora Objetiva, a coleção Devorando Shakespeare. Durante sua curta vivência, a coleção contemplou exclusivamente comédias shakespearianas e publicou ainda mais dois títulos: A décima segunda noite (2006), adaptação de Noite de reis ou o que quiserem (1601-02) escrita pelo ilustre Luis Fernando Veríssimo, e Sonho de uma noite de verão (2007), reescritura da comédia homônima (1595-96), assinada pela roteirista Adriana Falcão.

Antes de examinar com profundidade o romance de Furtado e a relação que o mesmo estabelece com a obra que se propõe adaptar, é preciso ter em mente alguns pontos importantes, como as implicações presentes no lema da coleção e os aspectos envolvidos na transposição de comédia elisabetana para romance brasileiro. Para isso, recorreremos às considerações levantadas no artigo "Reescrituras de Shakespeare na Ficção Brasileira Contemporânea" (MEDEIROS, 2011).

Tendo a devoração como mote, a coleção da editora Objetiva dialoga ativamente com um conceito ligado ao modernismo brasileiro: o da antropofagia. A palavra "devorar" traz consigo a ideia de processo de "deglutição antropofágica", i.e., assimilar itens culturais estrangeiros para, depois, regurgitá-los em forma de objeto novo e singular. Tal prática envolve, portanto, um caráter intertextual, dialógico, híbrido e polissêmico por natureza - algo que precede e termina por englobar a noção de adaptação.

A escritora estadunidense Adrienne Rich defende, em seu artigo "When We Dead Awaken: Writing as Re-vision", que "devemos conhecer os textos do passado e conhecê-los de forma totalmente diferente da que

\footnotetext{
2 Ao longo deste artigo, as citações da peça e do romance levarão apenas as iniciais "TAP". Por estarmos tratando de obras homônimas, a indicação do ato e da cena servirão para criar uma distinção entre as citações da peça e as do romance.

${ }^{3}$ TAP, p. 28.
} 
havíamos conhecido até então; não devemos perpetuar a tradição e, sim, acabar com o poder que ela exerce sobre nós" (1972, p. 19) ${ }^{4}$. A atitude proposta consiste em ver a obra com novos olhos e lidar com um texto antigo com uma nova perspectiva crítica (Cf. RICH, 1972, p. 18). A posição de Rich é corroborada por especialistas da área de estudos da adaptação, como Linda Hutcheon e Julie Sanders, que veem a prática de adaptação como uma atividade que deve estar pronta para abrir mão da fidelidade com o intuito de se engajar em um jogo intertextual mais amplo e complexo.

Em seu livro Adaptation and Appropriation, Sanders identifica as peças de Shakespeare como um notório foco de revisitações e atualizações, com obras que as transformam em poemas, romances, filmes, animações e até mesmo comerciais de televisão (Cf. SANDERS, 2006, p. 46). A autora também menciona o debate sobre a suposta fidelidade que as adaptações "devem" ao texto-fonte, afirmando que, em geral, "é justamente no ponto de infidelidade que acontecem os atos mais criativos de adaptação e apropriação" 5 (SANDERS, 2006, p. 20).

Na mesma linha, Hutcheon, em A Theory of Adaptation, concebe a adaptação não como reprodução sistemática - atitude que, segundo a autora, é conservadora e ultrapassada -, mas como atividade criativa que pode envolver intenções variadas e muito diferentes da mera repetição, como a homenagem ou o apagamento do texto original. Na obra, a teórica canadense vê adaptações como aqueles textos que são compostos de uma vasta gama de ecos, citações e referências (Cf. HUTCHEON, 2006, p. 6).

A adaptação é definida por Linda Hutcheon como produto e processo. Como produto, ela é "uma transposição extensiva e confessa de uma ou mais obras", uma transcodificação que "pode envolver uma mudança de meio (de poema para filme), de gênero (de épico para romance) ou de

\footnotetext{
4 Tradução nossa para: "We need to know the writing of the past, and know it differently than we have ever known it; not to pass on tradition but to break its hold over us."

5 Tradução nossa para: "It is usually at the very point of infidelity that the most creative acts of adaptation and appropriation take place."
} 
enquadramento e, consequentemente, também de contexto" 6 (HUTCHEON, pp. 7-8). Já como processo, a adaptação é vista, primeiro, como criação - um ato de (re)interpretação e (re)criação (Cf. HUTCHEON, pp. 7-8) - e, depois, como recepção, na qual a adaptação aparece como um palimpsesto que, por meio de repetições e variações, traz à tona a lembrança de outras obras (Cf. HUTCHEON, p. 27).

A teórica nos lembra também que adaptações estão longe de serem um produto exclusivo do nosso tempo e têm como adeptos nomes tão conhecidos quanto os de Ésquilo (aprox. 535 a.C. - 456 a.C), Jean Racine (1639 - 1699) e Johann Wolfgang von Goethe (1749 - 1832). Nesse enorme grupo de adaptadores, o nome de William Shakespeare novamente ganha destaque, exibindo um conjunto de obras que são, em sua vasta maioria, creditadas a fontes diversas.

Tendo em vista o que vimos até agora, o que significaria devorar Shakespeare? É possível dizer que devorar "é antes usar Shakespeare a nosso serviço que prestar obediência a ele" (MEDEIROS, 2011, s.p.). Com a cultura brasileira contemporânea como mediadora, o procedimento apropria ferramentas, materiais e temas para criar algo novo, algo nosso. Trata-se, portanto, de uma transformação de materiais em recursos simbólicos para falar, de um jeito bem brasileiro, em conjunto com o Bardo.

Devorar, nesse caso, também é transpor a história: repensar recursos e ferramentas para que se possa manusear o enredo e contá-lo em um meio diferente. No caso da transposição da comédia para o romance, temos, em primeiro lugar, mudanças na forma de engajamento. Em vez de ser exibida, a história passa a ser narrada: tudo o que antes era visto e vivido em tempo real, passa a ser descrito, condensado e explicado pela figura do narrador. Ganha-se espaço para uma linguagem mais apta a contemplar a subjetividade dos personagens e a complexificá-los. Além disso, temos uma diferença no tratamento dos personagens. No geral, a comédia conta com tipos comuns, com pouca ou nenhuma mobilidade social, enquanto o romance tende a privilegiar o desenvolvimento de determinado indivíduo,

\footnotetext{
${ }^{6}$ Tradução nossa para: "An adaptation is an announced and extensive transposition of a particular work or works. This "transcoding" can involve a shift of medium (a poem to a film) or genre (an epic to a novel), or a change of frame and therefore context."
} 
muitas vezes em conflito com o âmbito social em que se enquadra. A previsibilidade das comédias - com enredos bastante codificados e repletos de quiproquós, em geral com casamentos como desenlace também dá lugar a uma maior variedade no romance.

Tais desafios, longe de serem os únicos, fazem da adaptação um processo traiçoeiro, que exige muito planejamento e engenho, mas que não deve ser visto como algo inferior à obra da qual deriva. A presença de uma história, o "núcleo de sentido" defendido por Hutcheon em seu estudo, torna a obra passível de ser retransmitida e remodelada a novos meios de acordo com diferentes objetivos. Sendo assim, faz-se conveniente lembrar, mais uma vez, a importância da atitude livre de timidez, reverência e sentimento de inferioridade por parte do adaptador e da atitude livre de valorações, purismos e paternalismo por parte da crítica.

Pois essa é exatamente a atitude adotada por Jorge Furtado em Trabalhos de amor perdidos. O autor costura o desenvolvimento dos personagens, a exploração da obra de Shakespeare pelo protagonista e os acontecimentos da trama, misturando constantemente elementos shakespearianos com elementos de sua autoria. Assim, ele passa de "conduzido" a "condutor". No romance, Shakespeare "migra da condição de 'fonte', 'matriz', para a condição de objeto - de curiosidade, interesse, dificuldade, desafio" (MEDEIROS, s.p.). Em vez de seguir à risca os acontecimentos do texto-fonte, Furtado deixa de lado ideias como "respeito/desrespeito" e "fidelidade", ficando livre para evocar ecos, fazer recortes e propor analogias criativas, como veremos adiante.

\section{Trabalhos de amor perdidos (1595-96) e o banquete de linguagem shakespeariano}

Composta no começo da carreira de Shakespeare, Trabalhos de amor perdidos conta com elementos, temas e tipos que aparecerão mais tarde em peças mais conhecidas, como a estrutura da "peça-dentro-da-peça" (mise en abyme), situações em que a energia sexual vem à tona por meio de jogos de palavras de casais enamorados, trocadilhos jocosos que evocam imagens 
eróticas e "lembretes sombrios de que a morte cerca a comédia humana e os prazeres diários"7 (GARBER, 2005, p. 213).

A história se inicia com o Rei Ferdinando e três jovens nobres Berowne, Longaville e Dumain - se reunindo em Navarra para fazer um voto que é, ao mesmo tempo, um tanto presunçoso e inocente. Juntos, os quatro juram se afastar das experiências mundanas por três anos para se dedicarem por completo à contemplação das "artes da vida" (TAP, 1.1, p. 13) e fazer da corte de Navarra uma "pequena academia" (TAP, 1.1, p. 13). Assim, eles assinam um contrato que os impede de receber mulheres no castelo, os obriga a jejuar e a dormir apenas três horas por noite. Ambiciosa por si só, a promessa dos homens se torna um desafio ainda mais difícil de ser alcançado quando a Princesa da França chega com suas damas de companhia - Maria, Katherine e Rosaline - para negociar a posse da Aquitânia em nome de seu pai. Não tarda até que os homens encontrem uma forma de burlar o próprio voto, se encontrem com as damas no pátio real e, é claro, se apaixonem perdidamente por elas. As mulheres, já cientes do voto tomado por seus pretendentes, não perdem a oportunidade de se divertir com a situação. E, como se as intrigas amorosas não fossem o bastante, o cenário cômico se completa com a presença de Tonto, Melão e Mariposa (típicos bobos e clowns shakespearianos que comentam com agudeza os ridículos que testemunham), Dom Adriano de Armado (um espanhol dotado de dicção afetada e vocabulário pomposo), Holofernes (um professor arrogante que vive citando autores latinos e demonstrando todo o conhecimento que julga ter) e Sir Nataniel (um cura pseudointelectual e amigo de Holofernes).

Ainda que se apresente como um verdadeiro inventário de temas e artifícios que serão plenamente desenvolvidos em obras posteriores, como Muito Barulho por Nada e Sonho de uma Noite de Verão, Trabalhos de amor perdidos exibe algumas idiossincrasias. Em primeiro lugar, esta early comedy é uma das quatro peças de Shakespeare cujo roteiro é original. Grande parte dos especialistas parece concordar que a peça teria sido composta para uma apresentação privada, possivelmente na residência do conde de

\footnotetext{
${ }^{7}$ Tradução nossa para: “The stark reminders that death frames human comedy and daily pleasures."
} 
Southampton (Cf. HELIODORA, 2014, p. 7) - fato que também explicaria a sofisticação do tom e do enredo da peça. No entanto, é importante atentar para o fato de que, apesar do enredo ser inédito, há evidências de que Shakespeare teria se inspirado em fatos históricos para nomear seus personagens. Na introdução à edição Saraiva de bolso da peça, a crítica e tradutora Bárbara Heliodora aponta que, em 1578, Margarida de Valois, mais conhecida como Rainha Margot, foi a Nérac, uma região ao sudeste da França, visitar seu ex-marido, Henrique IV de Navarra. Assim como tantas outras, essa viagem foi feita na companhia de Catarina de Médicis, sua mãe, e de jovens nobres e belas - situação que levou o grupo a ficar conhecido como "esquadrão volante". Heliodora ressalta ainda que embora o nome do rei tenha sido mudado (nunca houve um Ferdinando de Navarra), os nomes de seus companheiros foram tirados de personagens também da época, como o marechal Biron (na peça, Berowne), o duque de Longueville (agora Longaville), ambos comandantes das tropas de Henrique de Navarra, enquanto o duque de Mayenne (agora Dumain) comandava seus opositores. (2014, p. 8)

Trabalhos de amor perdidos também se destaca das demais comédias shakespearianas por ser a única que termina em tom grave e atmosfera sombria. O desfecho tradicional, com casamentos e retorno à ordem, é substituído por tarefas impostas aos quatro homens pelas quatro mulheres e um aviso de morte. As festividades que ocupam o encerramento da peça são interrompidas por um mensageiro que informa à Princesa que o Rei da França morreu, motivando a saída repentina do grupo de damas. Os trabalhos de amor são perdidos e tudo que resta é uma promessa: se, passado um ano de distância entre os pares recém-formados, o sentimento persistir, os casamentos acontecerão. Rosaline instrui Berowne: "Livre-se do amargor desse seu cérebro, / E assim então me ganha. / (...) / Terá o ano inteiro, mês por mês, / De visitar os mudos, e assim mesmo / Conversar com gemidos" (TAP, 5.2, p. 127). Diante do final atípico, Berowne observa: “O fim não é o das peças antigas; / Ninguém casou; tivessem mais bondade, / Teríamos comédia de verdade" (TAP, 5.2, p. 127). Depois que todos se separam, o tom melancólico atinge seu ápice com a melodia que 
encerra a trama. De fato, "as palavras de Mercúrio são duras depois da canção de Apolo. Vocês, pra lá; nós, pra cá" (TAP, 5.2, p. 130).

Outro fator que faz de Trabalhos de amor perdidos uma comédia especial é o destaque que a consciência metadiscursiva ganha na trama. Além de ser meio de construção de universo fictício, de consumação de energia erótica e de estabelecimento de imagem social, a linguagem é posta em evidência durante toda a história, com personagens que comentam sobre a expressão alheia, se divertem com trocadilhos, deslizam em armadilhas linguísticas, se deleitam com as palavras e ponderam sobre os seus usos. Um ótimo exemplo é Dom Adriano de Armado. O cavalheiro "cuja fala, na moda, é um braseiro" (TAP, 1.1, p. 19) é tido por Longaville como um palhaço: “Tendo ele e Melão pra divertimento, / Dos três anos o estudo é um momento" (TAP, 1.1, p. 19). Berowne, por outro lado, reconhece a própria afetação retórica e termina afirmando que nunca mais confiará "em fala escrita, / Nem no que faz a língua de menino, (...) / Nem cortejar com serenata ou hino, / Frase pomposa, exagero bravio, / Hipérbole afetada, gongorismos, / Imagens falsas" (TAP, 5.2, p. 107).

Muitos críticos apontam o rebuscamento linguístico de Trabalhos de amor perdidos como fator que ajuda a explicar a baixa receptividade da peça entre o público ao longo dos anos. Na introdução à peça da edição da The New Cambridge Shakespeare, o professor William C. Carroll afirma que, ainda que existam evidências que assinalem uma certa popularidade nas três primeiras décadas de existência da peça, a comédia demonstra melhor desempenho como texto literário do que como texto dramático:

A vasta maioria das alusões e citações extraídas de Trabalhos de amor perdidos apontam para um texto que deve ser "lido" em vez de "atuado" - não apenas porque os sonetos dos nobres aparecem em coleções literárias, mas também porque muitas falas soltas (e nem sempre memoráveis) são reimpressas. (SHAKESPEARE, 2009, p. 39) ${ }^{8}$

\footnotetext{
${ }^{8}$ Tradução nossa para: “The vast majority of the allusions and quotations from Love's Labour's Lost point towards a 'read' rather than a 'performed' text - not only because of the lords' sonnets appearing in literary miscellanies, but also because so many individual (and not always remarkable) lines are reprinted."
} 
Carroll exemplifica uma série de meios em que o texto da peça circulava: commonplace books ${ }^{9}$, bibliotecas particulares, performances teatrais e públicas, coleções de poemas e epigramas - como The Passionate Pilgrim ${ }^{10}$ (1599) e England's Helicon (1600), as antologias elegidas por Carroll como as mais extensas apropriações da peça $(2009$, p. 39).

Seja por causa do rebuscamento da linguagem ou por causa das especificidades da obra, Trabalhos de amor perdidos se apresenta não como um quitute que agrada a todos e é devorado em segundos, mas como um banquete com várias opções de pratos: algo que devemos saborear aos poucos para descobrirmos detalhes que são maravilhosos e, à primeira vista, imperceptíveis. Com isso em mente, nos dedicamos agora a examinar o romance de Furtado e as modificações que o autor realizou para transportar a comédia para outro continente, outro século e outro gênero.

\section{Shakespeare devorado: Trabalhos de amor perdidos (2006)}

Assim como a história da qual deriva, o enredo do romance de Jorge Furtado tem como centro a tensão entre a dedicação aos estudos e os interesses erótico-amorosos dos personagens. Tudo começa quando Robin, protagonista da história, ganha uma bolsa de estudos da Fundação Roger Dod, uma instituição estadunidense que financia projetos com o objetivo de "popularizar a obra e as palavras de Shakespeare" (TAP, p. 11). A bolsa proporciona a Robin uma viagem a Inglaterra e a Dinamarca, assim como uma temporada de estudos nos Estados Unidos para desenvolver o seu projeto: uma peça que transforma Hamlet em comédia e imagina Yorick, o bobo da corte do Rei Hamlet, vivo e pronto para oferecer bons conselhos ao angustiado príncipe. Chegando a Nova York, Robin conhece outros bolsistas que também pretendem desenvolver projetos sobre o Bardo, como Gavil, Duck, Kanashii e Suhair - princesa jordaniana com quem já tinha cruzado em Bruxelas, durante uma parada rápida entre as escalas da viagem, e por quem se apaixona.

\footnotetext{
${ }^{9}$ Cadernos em que alunos da escola elisabetana - a grammar school - anotavam citações para memorizá-las e usá-las no futuro. Esses cadernos eram divididos por temas, como amor, amizade, vida e morte.

10 Coleção de 20 poemas atribuídos a William Shakespeare. Desses, apenas cinco são considerados autênticos: o soneto 138, o soneto 144 e três poemas retirados de Trabalhos de amor perdidos.
} 
O romance de Furtado se revela como uma obra em que a liberdade de manipulação é praticada desde o primeiro momento. A popularização da obra de Shakespeare - objetivo tanto de Furtado quanto de Robin serve de alicerce para a construção de uma estrutura que é, ao mesmo tempo, muito fragmentada e muito coesa. Registros, gêneros literários, e citações - tanto do Bardo quanto de outros autores e críticos luminares constroem a obra e dão a ela um aspecto único. A história avança entrecortando a experiência de Robin desde o momento em que ganha a bolsa, os e-mails trocados entre Gavil e sua mãe, uma série de comentários críticos, resumos detalhados de diversas peças shakespearianas - como Hamlet e Tito Andrônico - , comparações extensas de traduções e menções a especialistas consagrados, como o filósofo e crítico literário alemão Eric Auerbach (Cf. TAP, p. 15) e o poeta anglo-americano W. H. Auden (Cf. $T A P$, p. 140). Não menos óbvios e frequentes são os trechos que refletem o relacionamento do próprio autor porto-alegrense com o Bardo.

De adaptação, a obra se avoluma e se transforma em guia de exploração do rico universo shakespeariano. Furtado devora Shakespeare, saboreia detalhes, testa possibilidades. Durante o processo de regurgitação, as analogias aparecem como um dos pontos mais interessantes do romance, ampliando o escopo do conhecimento e aproximando Shakespeare dos dias atuais e da cultura brasileira. Furtado começa o jogo analógico de forma genial, descrevendo Feste - o bobo cantor de Noite de reis - como "o avô de Groucho Marx" (TAP, p. 14), grande comediante americano. Depois, ele passa por referências aos Beatles - "Só agora eu percebia o quanto o meu projeto era indefensável para quem conhece as peças, como um pot-pourri de Beatles que junta Lucy in the Sky With Diamonds e Yesterday" (TAP, p. 106). Finalmente, o autor conecta o Bardo ao Brasil, fazendo comparações muito adequadas. Um ótimo caso é o diálogo que acontece entre Suhair e Robin durante um dos encontros em que os dois discutem com mais detalhe seus projetos. Nele, Furtado faz duas analogias interessantes. A primeira é entre uma frase que aparece em Trabalhos de amor perdidos, "Jack 
hath not Jill"11 (TAP, 5. 2. 875), e o famoso samba de Chico Buarque, "Notícia de Jornal”: “Depois de medicada / Retirou-se pro seu lar / Aí a notícia carece de exatidão / O lar não mais existe / Ninguém volta ao que acabou / Joana é mais uma mulata triste que errou / Errou na dose / Errou no amor / Joana errou de João". A segunda relação é entre o soneto 138 e o samba "Falso amor sincero", de Nelson Sargento:

- A convencão teatral da época dizia que os acontecimentos narrados numa peça não podiam ultrapassar o período de uns poucos dias ${ }^{12}$. Um ano era tempo demais para uma peça. É uma piada, imagino que o público risse muito. Mas, ao mesmo tempo, é um final triste, eles se separam. "Jack hath not Jill."

- Entendi. Joana errou de João.

- O que é isso?

- A letra de uma música, um samba.

- Música brasileira. Já vi o carnaval na televisão. As letras são boas?

- Algumas são. “Nosso amor é tão bonito, ela finge que me ama, eu finjo que acredito..." Isso é um samba, parece um dos sonetos: "Quando jura ser feita de verdades, em minha amada creio, e sei que mente..."

(TAP, p. 160)

É interessante observar que essas analogias são apresentadas em destaque, sendo estudadas e explicadas pelo protagonista tanto no diálogo da trama quanto em notas explicativas.

Apesar de exibir detalhes que indiquem a aproximação com o textofonte desde o momento inicial, a obra se desenvolve de forma independente - e didática, pode-se dizer - , de modo a ser facilmente apreciada até mesmo por aqueles sem nenhum conhecimento prévio da comédia da qual deriva ou da produção shakespeariana como um todo. A intertextualidade começa a se fazer notar com força apenas no décimo capítulo da história, intitulado "O numeroso exército dos apetites sensuais". A inserção acontece de forma bastante natural, com a maioria

\footnotetext{
${ }^{11}$ Em nota explicativa, Furtado apresenta várias traduções para a citação. Delas, a que mais se aproxima da versão original é a de F. Carlos de Almeida Cunha Medeiros e Oscar Mendes: "João não se casa com Joana" (TAP, p. 159)

12 Suhair se refere à regra mimética das três unidades (tempo, espaço e ação), postulada por Aristóteles e amplamente aceita durante a Renascença e épocas posteriores.
} 
dos personagens do romance já delineados. No bar, em meio a cervejas e anedotas, Duck propõe: "Vamos fazer um brinde. Um brinde não: um pacto!" (TAP, p. 67). Depois de recitar a cena de abertura de Trabalhos de amor perdidos, Duck anuncia: "Em nome de William Shakespeare, o Deus da nossa idolatria, nós aqui juramos, por quatro meses, estudar e trabalhar com afinco e determinação!" (TAP, pp. 68-69) e exclui, assim como na peça, o contato com mulheres, causando tanto espanto em Robin quanto o rei causa a Berowne.

Para os leitores que têm familiaridade com a peça shakespeariana, é possível explicitar uma série de afinidades que demonstram a criatividade e engenhosidade do autor. A primeira e mais óbvia fica por conta dos próprios nomes. Em uma inversão de sílabas, Biron - grafia alternativa para Berowne, adotada por edições como a The Oxford Shakespeare, e nome do marechal no qual o personagem cômico é inspirado - se transforma em Robin. Por meio de uma simples redução, "Longaville" se torna "Gavil”. Já a relação de Duck com seu correspondente shakespeariano, Dumain, fica visível não através de seu nome, mas de seu estado natal: o rapaz é natural "do Maine". A localização da história, a propósito, participa do mesmo jogo dialógico com o texto-fonte. Assim como Navarra se torna - ou melhor, chega perto de se tornar - uma corte dedicada à nutrição do intelecto, Nova York se resume, para o grupo, em uma cidade acadêmica: um lugar no qual eles devem passar quatro meses estudando para realizarem o que propuseram em seus projetos. Robin pretende montar uma comédia. Duck, um programa de rádio com temática erótica e Gavil, um site de aconselhamento. Ainda que de forma muito sutil, os projetos dos bolsistas não deixam de ilustrar a ideia de que Shakespeare inspira leituras e abordagens tão diferentes quanto os tipos de personalidade que existem no mundo.

As conexões não param por aí. Os três personagens principais também recebem pares femininos. Robin se apaixona por Suhair que, assim como Rosaline, é morena, tem olhos negros e mostra maturidade e intelecto superiores aos do apaixonado. Duck começa uma relação fervorosa e para lá de cômica com Silvia, uma loira de olhos verdes e seios fartos que trabalha na rádio do Congresso. Gavil, por sua vez, é pareado com a mãe, 
Karen, uma professora de literatura inglesa com quem demonstra ter uma relação próxima e de quem sempre recebe conselhos inspirados em Shakespeare. Um ótimo exemplo disso é o trecho em que o conselho é extraído do próprio texto-fonte: “Estudar não é tudo: 'Os padrinhos terrestres da luz pura, que aos astros sabem dar nomes em messe, não têm nas belas noites mais ventura do que o pastor que a todos desconhece'" (TAP, p. 21).

É interessante notar, no entanto, que a relação com o texto-fonte se dá sempre em uma mistura de semelhança e diferença. O par Robin e Berowne ilustra essa situação de forma brilhante. A rapidez para fazer troças, por exemplo, é algo que os dois personagens compartilham. Na peça, Rosaline observa: "seu olhar põe em marcha seu espírito; pois tudo aquilo que o primeiro capta o outro transforma em chistes e risadas" (TAP, 2.1, p. 36). Já no romance, Suhair o descreve como um tipo ridículo, um "Bom Robin, um palhaço inofensivo" (TAP, p. 108). No entanto, diferentemente de Berowne, Robin não é um nobre de pensamento ágil e língua afiada. Em vez disso, Robin é ator e diretor de teatro, encontra-se sem grandes perspectivas de vida e já carrega consigo alguns fracassos: um casamento falido e uma carreira que, na melhor das hipóteses, pode ser classificada como medíocre.

É justamente nos casos em que não existem ligações aparentes que a engenhosidade de Furtado no exercício de adaptação de um autor canônico se mostra com maior evidência. Furtado elabora uma obra que se adequa às convenções do novo gênero, cria espaço para o desenvolvimento de novos personagens e elimina elementos que soariam forçados e prejudicariam a fluidez do enredo. Ao determinar o ritmo da própria história, o autor consegue introduzir detalhes que ostentam uma intertextualidade sofisticada e se provam fruto de uma leitura rica e fértil. Um grande exemplo dessa intertextualidade é a reelaboração das cartas, da metadiscursividade e do final melancólico da trama.

O primeiro caso que vale a pena ser citado é o emprego de um dos gêneros textuais mais comuns durante a modernidade nascente, a época de Shakespeare: o gênero epistolar. Em Trabalhos de amor perdidos, as cartas figuram como modo de comunicação e instrumento para situações de 
confusão e posterior revelação. Dom Adriano de Armado, por exemplo, vê na carta que manda ao Rei Ferdinando uma excelente oportunidade para demonstrar seu talento com as palavras. De fato, elas aparecem em cena antes dele mesmo, por meio de uma mensagem repleta de termos exuberantes e afetação hilária. Já na obra derivada, o que testemunhamos são mensagens enviadas por correio eletrônico: os e-mails entre Gavil e sua mãe. Na peça, as cartas carregam um potencial cômico. Já no romance, os emails são outra forma de devorar Shakespeare um pouco mais. As funções das mensagens são bem diferentes, sim, mas são igualmente relevantes para as tramas às quais pertencem.

O segundo ponto digno de nota é o caráter metadiscursivo do romance, que se manifesta o tempo todo e em níveis diferentes. Em ampla escala, vemos os objetivos de Furtado e de Robin se alinharem a ponto de ambos explicarem, simultaneamente, o propósito do livro e do projeto de estudo. Já em um nível menos superficial, temos personagens que se interessam avidamente pela linguagem. A mãe de Gavil, ecoando Holofernes ainda que de uma forma muito mais neutra e menos pejorativa, está sempre falando sobre literatura e citando Shakespeare. Enquanto o nome hispânico do professor De La Vega reflete uma proximidade com Dom Adriano de Armado, sua personalidade extravagante também nos remete a uma proximidade com Holofernes, uma vez que o mestre exibe "ótima memória" e declama "longas citações" e poemas que o levam "às lágrimas com frequência e intensidade excessivas" (TAP, p. 132). Robin, por sua vez, está sempre comentando sobre suas limitações na segunda língua - "Cometo erros horríveis quando falo e imagino que me suponham idiota e não apenas monoglota, por isso prefiro falar pouco" (TAP, p. 17) - e sobre as situações constrangedoras em que se mete por causa dessas mesmas limitações: “Algumas peças eu só li uma vez, mal, e há muito tempo, sempre em português. Muitas vezes eu não conseguia identificar as citações em aula por só conhecer o texto em português" (TAP, pp. 130-131). Mas a atenção que Robin dedica à linguagem não é motivada somente por suas limitações na língua inglesa. Ao longo do romance, Robin aparece comentando e ponderando sobre os significados das palavras, como quando fala: "explicou que o nome dele, kanashii, significa triste e que é 
representado pela mistura de dois outros ideogramas, que significam coração e oposto. Triste é isso: o oposto do coração" (TAP, p. 93).

$O$ desfecho do romance de Furtado também faz uma conexão interessante com a comédia que se propõe adaptar. Em vez da morte de um parente querido, o Rei da França e pai da Princesa, a história se encerra com os ataques terroristas que aconteceram em 11 de setembro de $2001 \mathrm{em}$ Nova York. Robin fica sabendo que Suhair está deixando os Estados Unidos às pressas, levada por homens do governo. O tom melancólico do cenário ganha uma nuance que ultrapassa a temática romântica e assume, assim como na peça, uma perspectiva mais ampla e sombria:

Um pequeno papel amarelo veio voando em minha direção. Era um postit, aqueles papeizinhos com uma linha de cola, para recados. Caiu no chão à minha frente, podia ter vindo dos escombros dos prédios ou podia já estar na rua, mas parecia ter vindo dos prédios. (...) Agora era tarde, eu tinha decidido ler e, se voltasse atrás, as palavras que eu não leria também seriam inesquecíveis. Por não saber, melhor saber, agora era tarde. Me abaixei, peguei o papel, li o recado, escrito com caneta vermelha: 'eu já volto'. Era mentira." (TAP, p. 209)

A Rosaline do romance é obrigada a fugir antes de fazer qualquer recomendação ao seu par. Mas, ao vermos Robin parado próximo a escombros na cidade de Nova York, nos lembramos novamente do fato que a morte "cerca a comédia humana e os prazeres diários" (GARBER, 2005, p. 213).

\section{Considerações finais}

Citando Jean Paris, ensaísta francês e especialista em Shakespeare, a mãe de Gavil nos lembra que devemos permanecer fieis a Shakespeare, procurando-o "menos em sua pessoa do que em seu pensamento" (TAP, p. 37). E é nesse quesito que a obra de Furtado consegue triunfar e passar de transposição frouxa à adaptação equilibrada, exitosa e merecedora de atenção especial. Em Trabalhos de amor perdidos, Furtado compartilha com Shakespeare a capacidade de oferecer um enredo que é, ao mesmo tempo, novo e familiar. $\mathrm{O}$ autor presenteia os leitores com doses homéricas de engenhosidade e irreverência que transformam o romance em uma leitura 
agradável e adequada para todos os tipos de público, entretendo desde aqueles que têm total familiaridade com o Bardo até os mais leigos. A receita base do romance pode até ser antiga, mas os temperos que Furtado adiciona nos instigam e nos deixam com gostinho de "quero mais".

\section{Referências}

FURTADO, Jorge. Trabalhos de amor perdidos. Coleção Devorando Shakespeare. Rio de Janeiro: Objetiva, 2006.

GARBER, Marjorie. Shakespeare after All. New York: Anchor Books, 2005. HELIODORA, Bárbara. Introdução. In: SHAKESPEARE, William. Trabalhos de amor perdidos. Tradução de Bárbara Heliodora. Rio de Janeiro: Nova Fronteira, 2014, pp. 7-10.

HUTCHEON, Linda. A Theory of Adaptation. London and New York: Routledge, 2006.

MEDEIROS, Fernanda T. de Coleção Devorando Shakespeare - reescrituras de Shakespeare na ficção brasileira contemporânea. In: HARRIS, Leila (Org.) Feminismos, identidades, comparativismos: vertentes nas literaturas de língua inglesa. Vol. IX. Rio de Janeiro: Eduerj, 2011, pp. 3758.

$\mathrm{RICH}$, Adrienne. When We Dead Awaken: Writing as Re-vision. In: College English, Vol. 34, No. 1, Women, Writing and Teaching (Oct., 1972). Illinois: The National Council of Teachers of English, 1972, pp. 18-30.

SANDERS, Julie. Adaptation and Appropriation. London and New York: Routledge, 2006.

SHAKESPEARE, William. Love's Labour's Lost. Ed. by William C. Carroll. The New Cambridge Shakespeare. Cambridge: Cambridge University Press, 2009.

. Trabalhos de amor perdidos. Trad. Bárbara Heliodora. Rio de Janeiro: Nova Fronteira, 2014.

\section{Resumo}

O presente artigo apresenta uma investigação minuciosa da adaptação para romance (2006), de Jorge Furtado, da comédia Trabalhos de amor 
perdidos (1595-96), de William Shakespeare. Por meio da observação de exemplos de correspondências e "infidelidades", propõe-se expor o complexo processo dialógico que ocorre entre as duas obras literárias, assim como explicitar a obra derivada como produto de uma (re)leitura aprofundada e um conhecimento íntimo do texto-fonte.

Palavras-chave: Estudos de adaptação; comédia shakespeariana; Trabalhos de amor perdidos; romance.

\begin{abstract}
This paper presents a comprehensive investigation of Jorge Furtado's novel adaptation (2006) of William Shakespeare's comedy Love's Labour's Lost (1595-96). Through the observation of examples of correspondences and "infidelities," it aims at displaying the complex dialogical process that occurs between the two literary works and evidencing the derived text as a product of a thorough (re)interpretation and a deep knowledge of the source-text.

Keywords: Adaptation studies; Shakespearean comedy; Love's Labour's Lost; novel.
\end{abstract}

